\title{
Study on Countermeasures that Reduce Reverse Bullwhip Effect in County Retail Supply Chain
}

\author{
Zhaohui Liu \\ College of Qinhuangdao \\ Northeast Petroleum University \\ Qinhuangdao, China \\ e-mail:lzhzdh@sohu.com
}

\author{
Yuwen $\mathrm{Wu}$ \\ Liren College \\ Yanshan University \\ Qinhuangdao, China
}

\begin{abstract}
The state of the county Retail Supply Chain is completely opposite to the bullwhip effect, which is called reverse bullwhip effect. The reason that causes reverse bullwhip effect is analyzed, the countermeasures are put forward that can reduce reverse bullwhip effect.
\end{abstract}

Keywords-the county territory; Retail Supply Chain; reverse bullwhip effect

\section{INTRODUCTION}

Developing rural market has become a develop strategy for retail enterprises in our country, many retailers started to seize county and county towns market. Because rural land in China city is vast, relatively scattered, the long distance between the villages, and relatively backward infrastructure, logistics network construction, the most supermarkets located at county seat. Limited by scale and market scope, its goods suppliers are always surrounding the county. The limitations of this county, determines this scope of supply chain management different from city supply chain management.

The bullwhip effect is refers to the consumer demand fluctuations along the supply chain step by step from bottom to top amplifier, due to the upstream inventory excess or production capacity magnification. Bullwhip effect was first put forward in 1963 by Forrester, since then, many domestic and foreign scholars have analyzed the bullwhip effect from different perspective, and put forward many effective methods to weaken this bullwhip effect.

Bullwhip effect has been recognized by academia and industry, therefore, the phenomenon opposite to bullwhip effect was found. That is, demand information is control even narrowed from downstream to upstream in the supply chain, eventually lead to the phenomenon of out of stock. This phenomenon is named as "reverse bullwhip effect". The existence of "inverse bullwhip effect" will damage all enterprises in the supply chain, including damage to the enterprise goodwill, loss of customer trust and deteriorating sales contradiction, etc. The purpose of this study is to analysis the reason that causes reverse bullwhip effect in county Retail Supply Chain , and hope to be able to find feasible solutions.

\section{STRUCTURAL ANALYSIS OF COUNTY RETAIL SUPPLY CHAIN}

The basic structure of the county Retail Supply Chain is shown as figure 1.

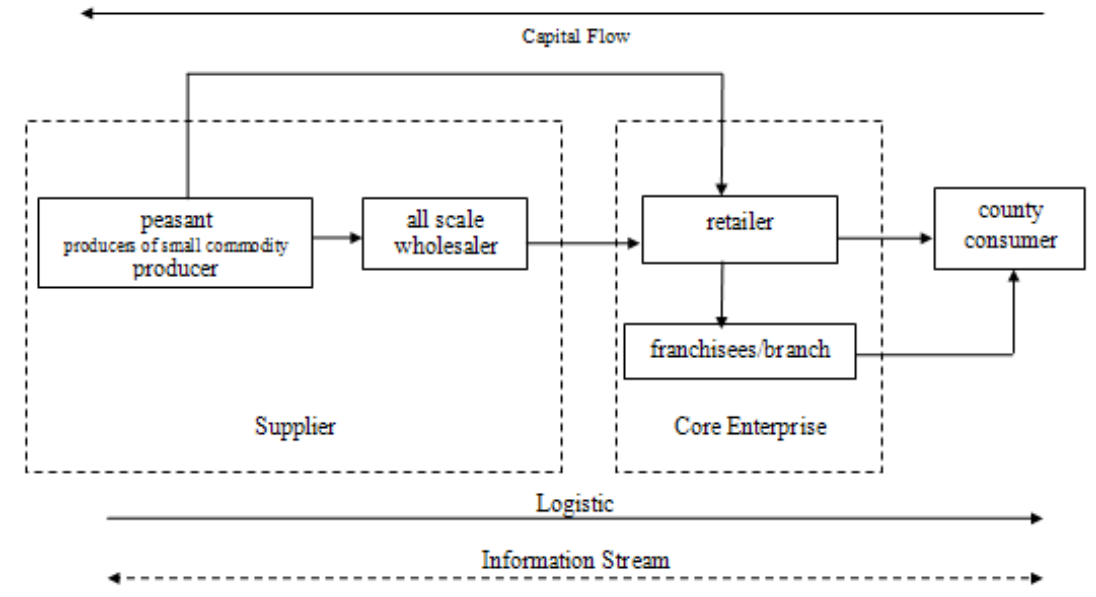

Figure 1. the Retail Supply Chain structure of the county 
In the upstream of the supply chain, suppliers consist of farmers, small commodity producers, manufacturers and distributors at all levels. Among them, the farmers mainly come from the county seat around the countryside, they supply to supermarkets and retail enterprises produced qualified fruits and vegetables and other agricultural products; Majority of commodity producers come from the surrounding rural areas, and most of them are originated in the original rural handicraft workshops. With the progress of technology, the increase in the strength, and gradually formed a small, in processing agricultural and sideline products consisting mainly of small commodity production enterprise. Manufacturers and distributors at all levels are responsible for supplying to retail enterprises such as home appliances, garments and other goods that can't be produced within the scope of county.

Core enterprise located in the middle reaches of the supply chain is mainly compost of retail enterprises and their franchise stores within the scope of the county. Most of retail enterprises located in the most bustling commercial center in the county, its main target market is the county seat consumer and part of the rural residents close to county seat. However, because the marketing strategy of retail enterprises is different, so its subordinate stores appear in one form or another, mainly in the form of franchise stores and branches.

Consumers in supply chain downstream consist of county residents and rural residents, due to the deviation of the residence, it's slightly different in consumer focus and consumption habits, most of county residents consumers are out of agricultural production activity, the variety in consumption of goods is similar to the urban residents, and with the gradual improvement of the quality of life and the increase of income, For high-end consumer ,preferences is a little high, and in recent years, the economic level has enhanced, all kinds of information has exchanged rapidly, thus making preliminary county residents consumption market perfect and increasingly mature. County resident consumers are more interested in he degree of fullness for commodity, price comparison, at a discount to buy a gift and loyalty points system. They also prefer to convenient consumption, fresh consumption and short time consumption; county countryside residents are still mainly engaged in agricultural activities, as a result, part of the basic means of livelihood and daily necessities don't need to enter the county retail supermarket to purchase, however, other consumer goods such as large appliances will need to enter the retail supermarket to purchase. At present, the rural residents of consumer demands great for this, but they attach less importance to the goods abundance, methods of promotion and so on. But they still have something in common, that is, they are very sensitive to price of commodities and show great interest in discount of the price and rewards of buying a gift.

\section{REASONS OF PRODUCING REVERSE BULLWHIP EFFECT} IN COUNTY RETAIL SUPPLY CHAIN

\section{A. Inaccuracy of demand forecasting}

Inaccurate demand forecast has directly caused the reverse bullwhip effect appeared on county Retail Supply Chain. In county Retail Supply Chain, upstream node member companies always make corresponding forecast of products requirements according to the requirements of downstream members order demand, but because of the negative effects of bullwhip effect, such as inventory backlog, the end retail enterprise is extremely sensitive to this, can't clearly understand and state bullwhip effect and what has caused it, only magnify the reason of inventory imbalances partly, for fear of too much inventory pressure, the management staff at all levels be told to reduce inventory, reduce the backlog of goods as far as possible to save costs, therefore, at the grassroots level the idea that "prefer to order some goods less rather than turn it into backlog". On the other hand, due to a lack of modern information management technology support, the staff of each node enterprise on the supply chain for the upstream enterprise order basis mainly depends on experience and feeling, and lack of scientific market demand forecast.

\section{B. The internal operational process in end retail is not reasonable}

Currently, most county retail enterprise organization structure is usually based on function division, this division method is not conducive for responsibility when out of stock. Actually, it involves purchasing department, warehouse department, receiving department, supermarket department, when replenishing, the supermarket tally clerk sorts through existing inventory count, then according to goods expected to need restocking, puts forward an replenishment order, and submits to the tally is in charge of check, and sends the list to the receiving department, after receiving the order, receiving department deals these received orders with the relevant statistical processing, concurrent to hand it out to the suppliers and relevant departments of supermarkets, then relevant departments check the booking after receipt of order, at the same time, the supplier should deliver the goods according to the order, after the goods delivered, by the inspector for inspection, and the compliance of goods are sent to the warehouse department, tally clerk puts them into the goods shelf according to the need for goods.

Due to lack of replenishment system support in most of county retail enterprises, tally, order and acceptance of the order is still in the manual processing phase, the order quantity and quality control completely depend on the degree of relevant worker's experience and whether he/she is meticulous, any negligence or lapse in judgment can lead to out of stock situation, namely this department setting method could bring about the mutual shuffle stalling of responsibility, finally unable to clear the division responsibility, thus to some extent exacerbated the reverse bullwhip effect. 


\section{Order lead time is too long}

At present, the development of the county Retail Supply Chain is in its primeval phase, compared with supply chain city, within the scope of the county, due to the constraints of low level specialization and socialization, small scale, low degree marketization, backward management level, as well as the limit of county market size and the enterprise itself supermarket scale, as a result, within the scope of the county, there are neither the third party logistics company responsible for the delivery of goods, supermarket retailers also do not have ability to self-built distribution center. So most retail enterprises have to take the goods by the supplier stores to send straight. Also due to market size restrictions, resulting in the lack of excellent suppliers, otherwise the commercial network density imbalance, the county downtown commercial outlets are more concentrated, chaos layout, forms of the same layout, which often appears that a supplier within the scope of county supplies for almost all of the retail enterprise, therefore, when the overall size of orders did not meet the delivery requirements for transportation economy or the supplier takes economical transportation into consideration, suppliers tend to artificially prolong order lead time, and the extension of the retail terminal is not informed ahead of time, even this extension will extend to next order cycle, and once the downstream enterprise stock is insufficient at this time, shortage is inevitable. Reverse bullwhip effect phenomenon caused by this reason, is very obvious in the part of the daily consumer goods.

\section{The impact of sales price promotion}

On county Retail Supply Chain, consumers in the downstream of the supply chain consist of county residents and rural residents, they are very sensitive to the commodity price, and they are interested in the discount and rewards of buying a gift and so on. Therefore, most retailers in the county frequently held promotional activities, and the result of each promotion will lead to many customers buying large quantities of goods one-time, and even cause the phenomenon of shortage, resulting in a false impression of customer demand amplification and demand distortion.

In county retail enterprises, retail terminal have strict control system for commodity inventory (especially for fast goods), this strict control caused conservative estimate of the commodity demand to a certain extent, and directly leads to the shortage of the orders in quantity, once the supermarket promotes on a large scale, when communicating with the manufacturers or suppliers salesman, they often ignore in time communication and feedback about goods in stock from other suppliers. In addition, when the worker of the manufacturers or suppliers held promotional activities, they maybe ignore the dynamic change of inventory hold at that time, and neglect the communication with this enterprise inventory distribution department, thus leading to can't meet the demand of supermarket enterprise order, finally sales terminal is out of stock.

\section{E. Lack of coordination}

Within the supply chain, because there is conflict of interest relationship between each node enterprise members, every one is not willing to share information involved in the business secret, this kind of "internal friction" greatly reduces the operating efficiency of the supply chain. Due to the relatively small county scale, various enterprises fight for market, this kind of interest conflicts is more acute, and there is more fierce competition between each other, therefore, within the county Retail Supply Chain, this kind of phenomenon is more obvious.

Taking supermarket a retail terminal as example, in the supermarket, tally clerk is responsible for the shelves of goods order, tally clerk is composed of two kinds of people, one is the supermarket staff, and another is salesman. Although tally clerk is uniformly managed by supermarket, but the salesman's salary is given by the vendor solicitor, so it appears the phenomenon of multiple management chapters - salesman should not only obey the supermarket rules, but also obey the superior salesman's management. It means that salesman should keep low level inventory, at the same time they should increase the order quantity as soon as possible, It is difficult for the salesman to grasp the balance.

If tally clerk is a supermarket clerk, due to its low level inventory requirement, supermarket clerk wouldn't worry about the performance, he/she even pay less attention to appearing out of stock, once having antinomies with the salesman, the phenomenon of out of stock will be more serious; If tally clerk is a salesman, their wages are completely determined by the clerk, due to the low level of job, clerk blindly emphasis on performance for clerk, it caused great pressure on the clerk, the forces between retailers and suppliers mutually penetrate and influence order quantity in different levels, with this contradiction intensified, it can also lead to sabotage phenomenon, finally terminal is out of stock.

\section{F. Low degree of information sharing}

At present, the information degree of each node enterprise on the county supply chain is quite lower; the level of information construction is quite low too, only achieved the primary use of bar code POS system, for real-time management system of goods, digital distribution center, electronic data management system, the retail enterprises in our country are just in the initial stage, so let alone enterprises within the scope of the county. Now the situation, to some extent, retarded the progress of information sharing. However, building information sharing platform and realizing information sharing on supply chain, is inevitable trend for the future partners to realize information sharing on county Retail Supply Chain, at the same time, it will greatly reduce the bullwhip effect in county Retail Supply Chain.

\section{COUNTERMEASURES THAT REDUCE REVERSE} BULLWHIP EFFECT IN COUNTY RETAIL SUPPLY CHAIN

\section{A. Optimization of hierarchical structure of supply chain}

Based on the previous analysis, the more levels the Retail Supply Chain have, the longer the supply chain is, the more 
complex the structure is, the greater the risk of out of stock is, therefore, optimization of hierarchical structure can largely reduce the risk of the reverse bullwhip effect in county Retail Supply Chain.

Each retail enterprise shall carry on the reasonable optimization according to own situation, and improve the low efficient supply chain structure, can start with reducing the minor participant and shorting supply chain length. According to its own process and need, The core enterprise in supply chain can divide the suppliers and sales outlets at a lower level, and reserve the main suppliers, including those participants who produce important value-added role for the final product sold, special hot product supplier, and give up some participants who have only part of support to the final product sold or the supplier whose products are not bestselling, By simplifying, supply chains will have a proper hierarchical structure, its length and width could reach a moderate level, according to the real needs and requirements of cooperation, county Retail Supply Chain could be set up.

\section{B. Improve the accuracy of the demand forecast}

\section{1) Correct understanding of the bullwhip effect}

The bullwhip effect refers to the phenomenon that when downstream enterprises were transmit information to upstream, there was information distortion and the distortion degree was enlarged step by step. There are a variety of reasons, and it is rather can be avoided by inventory control simply. Every enterprise in county supply chain must carry on the comprehensive understanding and learning, cannot simply boil down the cause of the phenomenon to the inventory problem, also can't taken it as the basis to limit low inventory levels.

2) Strengthen the correct guidance of relevant personnel on the enterprise supply chain

On the one hand, shortage management idea should be brought into the daily training, the aim is to make all employees, especially the grassroots employees to clear that what bad influence and serious harm shortage have to the enterprise, the enterprises also need to join replenishment process in the training, and perfect the evaluation index, and require personnel at the grass-roots level presenting statistical report on shortage of goods in time, to achieve real-time statistics; On the other hand, senior management need to correct their attitude towards shortage problem, once shortage occur, senior management must realize the shortage is caused by a variety of reasons, and should not simply boil down the problem to grassroots employees sense of responsibility, thus ignoring the other reasons.

3) shorten delivery time

The theory and practice have proved that the longer the order lead time was, the worse prediction accuracy was. Therefore, shortening the delivery time can greatly reduce the risk of producing inverse bullwhip effect in the county Retail Supply Chain. For suppliers in the county Retail Supply Chain, considering the reasons of economy of scale, normally, uncertain delivery time increased the risk of shortage. Therefore, Making reasonable delivery cycle, strengthening the audit to urge on and the contact with suppliers, and the delivery period stated clearly in the contract, if necessary, the ordering cycle should be detailed to day, and setting up the performance reward terms, increasing penalties for breach and other constraints.

\section{Optimize internal business processes in the retail end}

Improving and adjusting supermarket enterprise internal operation process structure, according to order process adjusting and reconstructing relevant departments, that is, merging and recombining purchasing department, warehouse department, receiving department, supermarket department four departments in accordance with the order process, forming tally department, information department and order management department three departments, tally department consists of the supermarket department and warehouse department, is mainly responsible for preparing purchase orders; Information department consists of personnel in charge of fax orders from previous receiving department, personnel related are mainly responsible for the statistical order and releases documentary to suppliers; Order management department consists of personnel from the purchasing department and receiving department who is in charge of the inspection early, personnel related are mainly responsible for checking whether there is any shortage phenomenon, especially, check whether the replenishment is in time. In this way, the enterprises can prevent mutual shuffle of responsibility when there is shortage and clear about the responsibility division.

\section{Improve the level of information sharing among supply chain enterprises}

Supply chain node enterprise should strengthen the contact and cooperation, to remove obstacles of information transfer between supply chain members, to increase the degree of information sharing, to form a seamless supply chain driven by customer needs, to achieve good coordination, to eliminate the influence of information wave is the key to operate supply chain efficiently. At present, for most enterprises in county Retail Supply Chain, it is impossible to completely achieve information sharing; however, this will be the inevitable trend in the future. The precondition of information sharing includes taking the advanced information technology, such as the Internet, EDI, e-commerce, etc. According to the status, the enterprises in county Retail Supply Chain should set out to introduce advanced technology, select consciously and train technical management personnel to make hardware reserves and talent reserves for the future information sharing.

\section{REFERENCES}

[1] Yu ShaoJun. Analysis of Weakening the Bullwhip Effect in Supply Chain. Journal of nanjing university of finance and economics, 2008,154(6):60-63.

[2] Cheng Yonghong. Analysis and Mitigation of Bullwhip Effect in Supply Chain. Logistics engineering and management,2010,32(12):81-85.

[3] Ma Yungao, Huang Yufei, Jiang Nengqian, Cao Wenjing. Bullwhip Effect Based on Retailers' and Customers' Forecasting Behaviors. System engineering,2011,29(8):14-20.

[4] Tang Xiangdong. Analysis of decision-making mechanism affect bullwhip effect in supply chain. Economic forum,2009(5):124-126. 
[5] Hu Jianbo. The causes of the bullwhip effect and countermeasures to weaken the bullwhip effect. Enterprise management,2011(8):77-79.
[6] Song Zhihui Li Tielin Liulin. The Mechanism of Bullwhip Effect and Countermeasures. Journal of shijiazhuang railway institute (social science edition) ,2009,3(4):20-24 